\title{
The phubbing phenomenon: a cross-sectional study on the relationships among social media addiction, fear of missing out, personality traits, and phubbing behavior
}

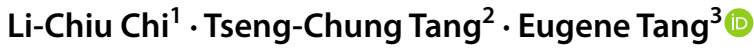

Accepted: 1 November 2021 / Published online: 30 January 2022

This is a U.S. government work and not under copyright protection in the U.S.; foreign copyright protection may apply 2021

\begin{abstract}
Pathological phubbing behavior has become an increasingly prevalent issue in recent years yet research surrounding these technological concerns remains scarce. The current study seeks to contribute to this limited body of research by providing insight into the antecedents of excessive and severe phubbing behavior and potential risk factors of pathological technology use as a whole. 938 undergraduate students participated in a cross-sectional study to determine whether demographic variables, personality traits, and degrees of social media addiction and fear of missing out could explain phubbing behavior. Participants responded to a survey that included the Bergen Social Media Addiction Scale (BSMAS), Fear of Missing Out Scale (FoMO), Ten-Item Personality Inventory (TIPI), and Phubbing Scale (Phubbing). Bivariate correlations identified that BSMAS and FoMO were significantly positively correlated with phubbing while TIPI displayed a significantly negative correlation with phubbing. Further, hierarchical multiple regression analyses established that BSMAS holds the most predictive power for phubbing while FoMO displayed a significantly less robust predictive power. TIPI was shown to be significant but served less to explain the variance in phubbing behaviors.
\end{abstract}

Keywords Phubbing · Communication disturbance · Phone obsession · Social media addiction · Fear of missing out · Personality traits

\section{Introduction}

The widespread use of smartphones that has emerged over the past century has undoubtedly seen numerous benefits; however, the convenience of smartphones and in turn, the rapidly growing accessibility of the worldwide internet has not been without its problems. One specific phenomenon the widespread accessibility of smartphones has caused is phubbing, which refers to an individual's obsessive use of the smartphone instead of having interpersonal conversations with other individuals in a social setting (Karadağ

Eugene Tang

tange1@berkeley.edu

1 College of Applied Arts and Sciences, National Formosa University, Yunlin, Taiwan

2 College of Management, National Formosa University, Yunlin, Taiwan

3 Department of Molecular and Cell Biology, University of California, Berkeley, CA, USA et al., 2015). Phubbing has become normative in modern-day communication (Karadağ et al., 2015; Chotpitayasunondh \& Douglas, 2018a) and has been cited to be at the intersection of many immediate issues on both an intrapersonal and interpersonal scale. Among them, numerous studies have found phubbing to be positively linked to social media addiction (Karadağ et al., 2015; Franchina et al., 2018; Błachnio \& Przepiórka, 2019; Nazir \& Bulut, 2019; Balta et al., 2020). Phubbing behavior has also been shown to be positively associated with other intrapersonal traits like the fear of missing out (FOMO) (Blanca \& Bendayan, 2018; Davey et al., 2018; Franchina et al., 2018; Balta et al., 2020). Studies investigating the potential role of personality traits on phubbing behavior have also concluded that certain personalities serve as risk factors while others serve as protective factors for phubbing behavior (Chotpitayasunondh \& Douglas, 2018b).

Social media, platforms and applications that enable social networking, community-based interaction, and content-sharing, has become pathological for some users due to their excessive use. For some, this may develop into an 
obsessive-compulsive, excessive, and unrestrained use of social media platforms (Young, 1999). In the majority of studies on phubbing behavior, among the leading predictors of this behavior are addictive tendencies, and perhaps most importantly, addiction to social media (Franchina et al., 2018; Błachnio \& Przepiórka, 2019; Nazir \& Bulut, 2019; Balta et al., 2020). In the same vein, Salehan and Negahban (2013) have also shed light on the pathological use of social media even at the expense of deteriorating interpersonal relationships caused by phubbing behaviors. Research on psychological factors associated with phubbing and social media addiction has also raised awareness over the fear of missing out as a predictor of phubbing behavior (Chotpitayasunondh \& Douglas, 2016; Blanca \& Bendayan, 2018; Davey et al., 2018; Franchina et al., 2018; Balta et al., 2020).

FoMO has been defined as "a pervasive apprehension that others might be having rewarding experiences from which one is absent," or "the desire to stay continually connected with what others are doing" (Przybylski et al., 2013, p.1). FoMO, or similarly, the fear of missing out on important information pertaining to friends on social media can be associated with smartphone overuse (Hong et al., 2012) and in turn, can lead to phubbing behaviors. This potential relationship between FoMO and phubbing behavior was confirmed by a study that determined FoMO drives excessive smartphone use and in turn, phubbing behavior in Flemish adolescents (Franchina et al., 2018). Subsequent research has also suggested that people high in FoMO are likely to overuse their smartphones and as a consequence, phub others to satisfy the need to stay connected online (Balta et al., 2020).

Previous studies have shown that certain individuals are more prone to having FoMO than others (Stead \& Bibby, 2017), and studies have also identified the TIPI (a 10-item measure of the Big Five personality dimensions) personality traits to be predictors of social media addiction (Kircaburun et al., 2020). Specifically, a person's propensity toward mobile phone addiction as well as excessive social media use has been shown by several studies to be predicted by levels of certain personality traits such as extraversion (Ehrenberg et al., 2008; Zamani et al., 2011; Andreassen et al., 2013; Zhou et al., 2016), agreeableness (Butt \& Phillips, 2008; Ehrenberg et al., 2008; Zhou et al., 2016), conscientiousness (Kayiş et al., 2016; Zhou et al., 2016), emotional stability (Bianchi \& Phillips, 2005; Zamani et al., 2011), and openness to experience (Zamani et al., 2011; Andreassen et al., 2013; Zhou et al., 2016). Subsequent studies have also identified the personality traits that serve as protective and risk factors for problematic social media and smartphone use (Kuss et al., 2013). This study suspects that personality traits, which have been extensively shown to relate to social media addiction and smartphone overuse, may be associated with phubbing behaviors. Unlike personality traits and social media addiction, the existing body of research involving the relationship between personality traits and phubbing behavior is still in its infancy. Moreover, no study to date has examined the complex interplay among social media addiction, FoMO, TIPI, and phubbing behaviors. To address this gap in empirical knowledge, this study will seek to provide a comprehensive framework of these factors on phubbing behavior as it could prove to be critical for appropriate interventions and preventions to be put in place in efforts to reduce pathological phubbing behaviors and problematic smartphone use as a whole. With the existing literature and the study objectives in mind, this study puts forth the following hypotheses (i) the problematic use of social media platforms is the most significant risk factor for phubbing behaviors, (ii) individuals high in FoMO are more susceptible to exhibiting phubbing behaviors, and (iii) certain personality traits would serve as protective factors against phubbing behaviors and others would serve as risk factors for phubbing behaviors.

\section{Materials and Methods}

\section{Participants and Procedure}

The research sample comprised 938 undergraduate students, $48.4 \%$ of these male and $51.6 \%$ female. $22.4 \%$ of the 938 students are in the first year, $32.6 \%$ the second, $22.7 \%$ the third, $20.7 \%$ the fourth, and $1.6 \%$ are beyond their fourth year. The distribution of their majors is as follows: $39.6 \%$ humanities and arts, $16.6 \%$ social sciences, business and law, and $44.3 \%$ STEM. Finally, $78.14 \%$ of participants completed the questionnaire via pencil-and-paper and $21.86 \%$ of participants completed the questionnaire via Google Forms.

The data collection period spanned from November 2020 to February 2021 and questionnaires were distributed using a convenience sampling method. Self-administered penciland-paper questionnaires were utilized in addition to online Google Forms in order to increase the response rate. Penciland-paper questionnaires were distributed during university lectures with the permission of faculty members. Prior to filling out the questionnaires, students received relevant details regarding the study (purpose of study, questionnaire structure, confidentiality assurance, etc.) and were required to tick a checkbox indicating informed consent before completing the questionnaires. The study participants did not receive compensation of any sort.

\section{Translation Procedure}

The four research scales, the Bergen Social Media Addiction Scale (BSMAS), Fear of Missing Out Scale (FoMO), Ten-Item Personality Inventory (TIPI) and Phubbing Scale 
(Phubbing), were translated from English to Mandarin Chinese by the authors of the present study, who are native speakers. The Mandarin Chinese versions of the research scales were then back-translated and compared following the protocol from Beaton et al. (2000). There were no discrepancies between the two.

\section{Instruments}

The Bergen Social Media Addiction Scale The Bergen Social Media Addiction Scale (BSMAS) is a six-item selfreport measure constructed by Andreassen et al. (2016) for evaluating the problematic use of social media within a 12-month period. The instrument adopts the six core components of addiction (e.g., "spent a lot of time thinking about social media or planned use of social media") proposed by Griffiths (2000), salience, mood modification, tolerance, withdrawal conflict and relapse, and is rated on a five-point Likert scale ranging from very rarely (1) to very often (5) with scores ranging from 6 to 30. A higher score on the BSMAS implies a greater risk of addiction to social media, and a BSMAS score over 19 suggests an individual is prone to developing a problematic use of social media (Bányai et al., 2017).

Furthermore, the scale has been confirmed as a unidimensional structure with time invariance (Chen et al., 2020) as well as measurement invariance from Hong Kong and Taiwan (Leung et al., 2020). The high internal consistency $(\alpha=0.85)$ of the BSMAS reflects its reliability (Bányai et al., 2017). The BSMAS has also been proven to be reliable and valid among Taiwanese participants (Chen et al., 2020; Leung et al., 2020). In the present study, the internal consistency of the translated BSMAS was 0.867.

Fear of Missing out Scale Fear of Missing Out scale (FoMO) is a one-factor ten-item self-report measure (e.g., "I fear others have more rewarding experiences than me") developed by Przybylski et al. (2013). Each item is rated on a five-point Likert scale ranging from Not at all true (1) to Extremely true (5), yielding a score ranging from 10 to 50. A higher overall score on the FoMO implies a higher level of FoMO in participating students.

The FoMO has satisfactory psychometric properties with high internal consistency $(\alpha=0.81)$, and the testretest reliability coefficient is 0.81 (Gokler et al., 2016). The FoMO was proved to be valid among Chinese students (Xie et al., 2018) and the translated FoMO is shown to be reliable in the present study with a Cronbach's $\alpha$ of 0.845.Ten-Item Personality Inventory For personality measurement, the Ten-Item Personality Inventory (TIPI) developed by Gosling et al. (2003) was employed to assess the Big Five personality traits (e.g., "Extraverted, enthusiastic"), namely extraversion, agreeableness, conscientiousness, emotional stability, and openness to experience. Each dimension is measured by two items on a seven-point Likert scale ranging from strongly disagree (1) to strongly agree (7), generating a composite score ranging from 2 to 14 for each trait. The trait with the highest composite score is then considered to be the dominant personality trait for the participant.

The TIPI has satisfactory psychometric properties with good internal consistency (Spearman-Brown' $r=0.29 \sim 0.74$ ) (Balcerowska, et al., 2020). The TIPI has been previously validated among Chile, Hong Kong, and Poland undergraduate university students (Przepiorka et al., 2020). The present study does not utilize Cronbach's Alpha coefficients but instead employs Spearman-Brown coefficients for its reliability test for the reason that Spearman-Brown coefficients account for the small number of items per dimension (Eisinga et al., 2013) as well as the opposite polarity of the two items per trait (Gosling et al., 2003). The Spearman-Brown coefficients for the extraversion, agreeableness, conscientiousness, emotional stability, and openness to experiences were $0.652,0.127,0.199$, 0.102 , and 0.335 , respectively.

Phubbing Scale The Phubbing Scale (Phubbing) developed by Karadağ et al. (2015) assesses phubbing behavior using ten items that can be classified into two subscales that include communication disturbance (Phubbing ${ }^{\mathrm{CD}}$ ) illustrated in questions 1-4 (e.g., "My eyes start wandering on my phone when I'm together with others") and phone obsession (Phubbing ${ }^{\mathrm{PO}}$ ) in questions 5-9 (e.g., "I don't think that I annoy my partner when I'm busy with my mobile phone"). Each question is rated on a five-point Likert scale ranging from never (1) to always (5), generating a composite score ranging from 10 to 50 , the higher the composite score, the more severe the student' s phubbing behavior. Scores exceeding 45 indicate a higher likelihood of phubbing (Karadağ et al., 2016).

During the process of translating the Phubbing Scale, we discovered that there exists repetition for item 2 (I am always busy with my mobile phone when I'm with my friends) and item 4 (I'm busy with my mobile phone when I'm with friends). Upon asking the developer of the Phubbing, Professor Karadağ, we reached the decision to eliminate item 2 from our translated version of the Phubbing.

The Phubbing has been shown to be reliable with its high internal consistency of $\alpha=0.87$ and 0.85 for Phubbing ${ }^{\mathrm{CD}}$ and Phubbing ${ }^{\mathrm{PO}}$, respectively (Karadağ et al., 2015) and has been validated among participants in Spain and Turkey (Balta et al., 2020; Blanca \& Bendayan, 2018). The internal consistency of the translated Phubbing in the present study was 0.88 and 0.85 for Phubbing ${ }^{\mathrm{CD}}$ and Phubbing ${ }^{\mathrm{PO}}$, respectively. 


\section{Statistical Analyses}

In this study, the analyses were carried out using SPSS 19 and AMOS 21. The normality of data distribution was assessed with skewness and kurtosis tests. To examine the construct validity evidence for the Phubbing Scale, this study performed a confirmatory factor analysis (CFA) through the maximum likelihood estimation approach. To evaluate its goodness of fit, this study computed chi-square $\left(\chi^{2}\right)$ and normed $\chi^{2}$. Additionally, this study utilized four approximate model fit indices and two information criteria to determine whether the measurement models fit the data sets well (Kline, 2011). Comparative fit index (CFI), incremental fit index (IFI), standardized root mean square residual (SRMR), and root mean square error of approximation (RMSEA) were used as absolute fit indices while the Akaike information criterion (AIC) and the Bayesian information criterion (BIC) were used as model selection criteria. Categorical variables were expressed as numbers and proportions whereas continuous variables were presented with means and standard deviations. Chi-square tests of independence were conducted for comparisons of categorical variables while independent samples $t$-tests and One-Way ANOVA tests were used for continuous variables. Pearson's correlations were utilized to determine the bivariate correlations between BSMAS, FoMO, TIPI traits, and Phubbing. Fisher's $r$-to- $z$ transformation was employed to investigate the significance of the differences between the magnitudes of the different assessments. The relationships of BSMAS, FoMO, TIPI traits, and Phubbing were further investigated using multivariate hierarchical regression models, which were controlled for potential confounders. In more detail, the Phubbing subscale scores (i.e., Phubbing ${ }^{\mathrm{CD}}$ and Phubbing ${ }^{\mathrm{PO}}$ ) and the Phubbing composite scores (Phubbing ${ }^{\text {OVERALL }}$ ) were used as the dependent variables while BSMAS, FoMO, and TIPI traits were utilized as independent variables; gender, class year, major, and questionnaire administration mode were treated as confounding variables. P-values were two-tailed for all tests and a probability value of $p<0.05$ was considered as the significance level.

\section{Results}

\section{Differences Based on Demographics}

Table 1 reveals the descriptive statistics of the research variables of this study. The coefficients of skewness and kurtosis were all within the recommended threshold (Garson, 2012). Therefore, it can be concluded that no serious problems for normality were present.

In addition, Table 2 shows that the mean scores of Phubbing and the scores on its subscales for male students were
Table 1 Descriptive analysis of the variables

\begin{tabular}{llll}
\hline Variable & Mean (SD) & Skewness & Kurtosis \\
\hline BSMAS score & $16.94(4.38)$ & .21 & .15 \\
FoMO score & $27.44(6.99)$ & .23 & -.06 \\
TIPI score & $39.80(4.96)$ & .12 & .43 \\
$\quad$ Extraversion & $8.42(2.50)$ & .08 & -.16 \\
Agreeableness & $6.64(1.85)$ & -.20 & .02 \\
Conscientiousness & $9.27(1.80)$ & .09 & .63 \\
Emotional Stability & $6.42(1.72)$ & .02 & .48 \\
Openness to Experiences & $9.06(1.87)$ & .21 & .42 \\
Phubbing ${ }^{\text {OVERALL }}$ & $24.21(5.57)$ & .21 & .34 \\
Phubbing $^{\text {CD }}$ & $9.35(2.88)$ & .44 & .25 \\
Phubbing $^{\text {PO }}$ & $14.86(3.46)$ & .08 & .05 \\
\hline
\end{tabular}

significantly higher than their female counterparts, with a respective 3.950, 5.026, and $2.185 t$ statistic. However, there exist no significant differences for Phubbing and its subscales on class year, major, and questionnaire administration mode.

BSMAS $=$ Bergen Social Media Addiction Scale; FoMO $=$ Fear of Missing Out Scale; TIPI $=$ Ten-Item Personality Inventory; Phubbing ${ }^{\text {OVERALL }}=$ the Phubbing Scale composite score; Extraversion, Agreeableness, Conscientiousness, Emotional Stability, and Openness to Experience were TIPI personality traits; Phubbing ${ }^{\mathrm{CD}}$ and Phubbing ${ }^{\mathrm{PO}}$ were two subscales of the Phubbing Scale.

\section{Construct Validity}

This study tested two models to examine construct validity: the one-factor model (Model 1F), in which all items were assessed as one common scale of Phubbing, and the twofactor model (Model 2F), in which items were divided into two factors reflecting the two subscales (Phubbing ${ }^{\mathrm{CD}}$ and Phubbing ${ }^{\mathrm{PO}}$ ) of Phubbing. As seen in Table 3, both models did not fit the data and were respecified inclosing the covariances between items (Model 1FC and Model 2FC). Chi-square difference model comparison tests indicated that there was a significant improvement in fit for Model $1 \mathrm{~F}$ and Model 1FC $\left(\Delta \chi^{2}(7)=605.469, p<0.01\right)$ and for Model 2F and Model 2FC $\left(\Delta \chi^{2}(5)=322.985, p<0.01\right)$. In addition, Models $1 \mathrm{FC}(\mathrm{RMSEA}=0.101, \mathrm{SRMR}=0.056$, $\mathrm{CFI}=0.93$, and $\mathrm{IFI}=0.93)$ and $2 \mathrm{FC}(\mathrm{RMSEA}=0.114$, $\mathrm{SRMR}=0.071, \mathrm{CFI}=0.906$, and $\mathrm{IFI}=0.906)$ fitted the data significantly. Furthermore, composite reliability was greater than 0.6 (Phubbing ${ }^{\text {OVERALL }}=0.909$, Phubbing ${ }^{\mathrm{CD}}=0.820$, and Phubbing $\left.{ }^{\mathrm{PO}}=0.846\right)$ and average variance extracted exceeded 0.5 (Phubbing ${ }^{\text {OVERALL }}=0.531$, Phubbing ${ }^{\mathrm{CD}}=0.538$, and Phubbing ${ }^{\mathrm{PO}}=0.525$ ), showing that the latent variables possessed ideal convergence ability (Fornell \& Larcker, 1981). 
Table 2 Demographic Characteristics and the Phubbing

\begin{tabular}{|c|c|c|c|c|c|c|}
\hline Characteristic & Mean Phubbing $^{\mathrm{CD}} \pm \mathrm{SD}$ & Stats $(p)$ & Mean Phubbing ${ }^{\mathrm{PO}} \pm \mathrm{SD}$ & Stats $(p)$ & $\begin{array}{l}\text { Mean } \\
\text { Phubbing }{ }^{\text {OVERALL }} \pm \text { SD }\end{array}$ & Stats $(p)$ \\
\hline \multirow[t]{2}{*}{ Gender } & $\begin{array}{l}\text { Phubbing }^{\mathrm{CD}} \text { (Male) } \\
=9.84 \pm 3.00\end{array}$ & $5.026(0.000)$ & $\begin{array}{l}\text { Phubbing }^{\mathrm{PO}} \text { (Male) } \\
=15.11 \pm 3.35\end{array}$ & $2.185(0.000)$ & $\begin{array}{l}\text { Phubbing }{ }^{\text {OVERALL }} \text { (Male) } \\
=24.95 \pm 5.59\end{array}$ & $3.950(0.000)$ \\
\hline & $\begin{array}{l}\text { Phubbing }{ }^{\mathrm{CD}} \text { (Female) } \\
=8.90 \pm 2.68\end{array}$ & & $\begin{array}{l}\text { Phubbing }{ }^{\mathrm{PO}} \text { (Female) } \\
=14.62 \pm 3.55\end{array}$ & & $\begin{array}{l}\text { Phubbing }{ }^{\text {OVERALL }} \text { (Female) } \\
=23.52 \pm 5.48\end{array}$ & \\
\hline \multirow[t]{5}{*}{ Class year } & $\begin{array}{l}\text { Phubbing }{ }^{\mathrm{CD}} \text { (First year) } \\
=9.28 \pm 2.80\end{array}$ & $1.478(0.207)$ & $\begin{array}{l}\text { Phubbing }{ }^{\mathrm{PO}} \text { (First year) } \\
=14.60 \pm 3.52\end{array}$ & $2.090(0.080)$ & $\begin{array}{l}\text { Phubbing }{ }^{\text {OVERALL }} \text { (First } \\
\quad \text { year) } \\
=23.88 \pm 5.71\end{array}$ & $0.783(0.537)$ \\
\hline & $\begin{array}{l}\text { Phubbing }{ }^{\mathrm{CD}} \text { (Second year) } \\
=9.57 \pm 2.81\end{array}$ & & $\begin{array}{l}\text { Phubbing (Second year) } \\
=14.90 \pm 3.38\end{array}$ & & $\begin{array}{l}\text { Phubbing }{ }^{\text {OVERALL }} \text { (Sec- } \\
\text { ond year })=24.47 \pm 5.41\end{array}$ & \\
\hline & $\begin{array}{l}\text { Phubbing (Third year) } \\
=9.48 \pm 3.03\end{array}$ & & $\begin{array}{l}\text { Phubbing }{ }^{\mathrm{PO}} \text { (Third year) } \\
=14.80 \pm 3.50\end{array}$ & & $\begin{array}{c}\text { Phubbing }{ }^{\text {OVERALL }} \text { (Third } \\
\text { year })=24.28 \pm 5.74\end{array}$ & \\
\hline & $\begin{array}{l}\text { Phubbing }{ }^{\mathrm{CD}} \text { (Forth year) } \\
=8.96 \pm 2.83\end{array}$ & & $\begin{array}{l}\text { Phubbing }{ }^{\mathrm{PO}} \text { (Forth year) } \\
=15.27 \pm 3.52\end{array}$ & & $\begin{array}{c}\text { Phubbing }{ }^{\text {OVERALL }} \text { (Forth } \\
\text { year) }=24.23 \pm 5.57\end{array}$ & \\
\hline & $\begin{array}{c}\text { Phubbing }{ }^{\mathrm{CD}}(\text { Fifth year or } \\
\text { beyond })=9.33 \pm 3.52\end{array}$ & & $\begin{array}{c}\text { Phubbing }{ }^{\mathrm{PO}}(\text { Fifth year or } \\
\text { beyond })=13.00 \pm 2.59\end{array}$ & & $\begin{array}{l}\text { Phubbing OVERALL } \\
\quad \text { (Fifth year or } \\
\text { beyond) }=22.33 \pm 5.57\end{array}$ & \\
\hline \multirow[t]{3}{*}{ Major } & $\begin{array}{r}\text { Phubbing }{ }^{\mathrm{CD}} \text { (Humanities } \\
\text { and Arts) }=9.30 \pm 2.93\end{array}$ & $0.894(0.409)$ & $\begin{array}{l}\text { Phubbing }{ }^{\mathrm{PO}} \text { (Humanities } \\
\text { and Arts) }=14.96 \pm 3.62\end{array}$ & $1.264(0.283)$ & $\begin{array}{l}\text { Phubbing OVERALL } \\
\text { (Humanities and } \\
\text { Arts) }=24.26 \pm 5.84\end{array}$ & $0.049(0.953)$ \\
\hline & $\begin{array}{l}\text { Phubbing }{ }^{\mathrm{CD}} \text { (Social Sci- } \\
\quad \text { ences, Business and Law) } \\
=9.14 \pm 2.79\end{array}$ & & $\begin{array}{l}\text { Phubbing }{ }^{\mathrm{PO}} \text { (Social Sci- } \\
\text { ences, Business and Law) } \\
=15.13 \pm 3.32\end{array}$ & & $\begin{array}{l}\text { Phubbing }{ }^{\text {OVERALL }} \text { (Social } \\
\text { Sciences, Business and } \\
\text { Law) } \\
=24.27 \pm 5.25\end{array}$ & \\
\hline & $\begin{array}{l}\text { Phubbing }{ }^{\mathrm{CD}} \text { (STEM) } \\
=9.48 \pm 2.86\end{array}$ & & $\begin{array}{l}\text { Phubbing }{ }^{\mathrm{PO}}(\mathrm{STEM}) \\
=14.67 \pm 3.37\end{array}$ & & $\begin{array}{l}\text { Phubbing }{ }^{\text {OVERALL }} \text { (STEM) } \\
=24.15 \pm 5.47\end{array}$ & \\
\hline \multirow[t]{2}{*}{ Administration mode } & $\begin{array}{l}\text { Phubbing }{ }^{C D} \text { (pencil-and- } \\
\text { paper) } \\
=9.37 \pm 2.87\end{array}$ & $0.400(0.690)$ & $\begin{array}{l}\text { Phubbing }^{\mathrm{PO}} \text { (pencil-and- } \\
\text { paper) } \\
=14.81 \pm 3.32\end{array}$ & $-0.810(0.418)$ & $\begin{array}{l}\text { Phubbing OVERALL (pencil- } \\
\text { and-paper) } \\
=24.18 \pm 5.41\end{array}$ & $-0.297(0.767)$ \\
\hline & $\begin{array}{l}\text { Phubbing }{ }^{\mathrm{CD}} \text { (Online) } \\
=9.28 \pm 2.91\end{array}$ & & $\begin{array}{l}\text { Phubbing }{ }^{\mathrm{PO}} \text { (Online) } \\
=15.03 \pm 3.94\end{array}$ & & $\begin{array}{l}\text { Phubbing }{ }^{\text {OVERALL }} \text { (Online) } \\
=24.31 \pm 6.18\end{array}$ & \\
\hline
\end{tabular}

Table 3 Fit indices for onefactor and two-factor models of the Phubbing

\begin{tabular}{llllllllll}
\hline Model & $\chi^{2}$ & $d f$ & $\chi^{2} / d f$ & RMSEA 90\% CI & SRMR & CFI & IFI & AIC & BIC \\
\hline $1 \mathrm{~F}$ & $816.472^{* *}$ & 27 & 30.240 & $0.177[0.166,0.187]$ & 0.111 & 0.710 & 0.710 & 852.472 & 939.639 \\
$2 \mathrm{~F}$ & $211.003^{* *}$ & 20 & 10.550 & $0.101[0.089,0.114]$ & 0.056 & 0.930 & 0.930 & 261.003 & 382.097 \\
$1 \mathrm{FC}$ & $600.072^{* *}$ & 26 & 23.080 & $0.154[0.143,0.164]$ & 0.109 & 0.789 & 0.789 & 638.072 & 730.103 \\
$2 \mathrm{FC}$ & $277.087^{* *}$ & 21 & 13.195 & $0.114[0.089,0.114]$ & 0.071 & 0.906 & 0.906 & 325.087 & 441.337 \\
\hline$* * p<0.01$ & & & & & & & &
\end{tabular}

\section{Correlation Analysis}

Table 4 shows that BSMAS and FoMO were significantly positively correlated with Phubbing ${ }^{\mathrm{CD}}$, Phubbing ${ }^{\mathrm{PO}}$, and Phubbing OVERALL ( $r=0.413$ to 0.619 ) whereas TIPI traits, agreeableness, conscientiousness, emotional stability, were significantly negatively correlated $(r=-0.007$ to -0.278). The extraversion and openness to experience TIPI traits, specifically, had a significant negative correlation with Phubbing ${ }^{\mathrm{CD}}$ and Phubbing OVERALL but exhibited no correlation with Phubbing ${ }^{\mathrm{PO}}$. To conclude, higher levels of BSMAS and FoMO suggest a higher severity of phubbing behaviors, and higher levels of TIPI suggest a reduced severity of phubbing behaviors.
The magnitudes of correlations between BSMAS and Phubbing ( $r=0.519$ to 0.619 ) were larger than those between FoMO and Phubbing ( $r=0.413$ to 0.487 ). To compare correlations, Fisher's $r$ to $z$ transformation was adopted to investigate the significance of the difference between magnitudes of the associations. The results revealed that for the respective Phubbing ${ }^{\mathrm{CD}}$, Phubbing $^{\mathrm{PO}}$, and Phubbing OVERALL, the correlations with BSMAS were significantly stronger than the correlations with FoMO, with $\mathrm{z}$ test statistics of $3.757(p=0.001), 2.935(p=0.003)$, and 4.389 ( $p=0.000)$, respectively. The Fisher's $r$ to $z$ transformation thus confirms that the independent variable BSMAS has a stronger correlation with Phubbing than FoMO does. 
Table 4 Correlation matrix between study variables

\begin{tabular}{|c|c|c|c|c|c|c|c|c|c|c|}
\hline Variable & 1. & 2. & 3. & 4. & 5. & 6. & 7. & 8. & 9. & 10. \\
\hline 1.BSMAS & - & & & & & & & & & \\
\hline 2.FoMO & $.456^{* *}$ & - & & & & & & & & \\
\hline 3.Extraversion & $.093^{* *}$ & .022 & - & & & & & & & \\
\hline 4.Agreeableness & $-.164^{* *}$ & $-.219^{* *}$ & $-.282^{* *}$ & - & & & & & & \\
\hline 5.Conscientiousness & $-.184^{* *}$ & $-.082^{*}$ & $.157^{* *}$ & $-.190^{* *}$ & - & & & & & \\
\hline 6.Emotional Stability & $-.082^{*}$ & $-.138^{* *}$ & $.163^{* *}$ & $.324^{* *}$ & $-.210^{* *}$ & - & & & & \\
\hline 7.Openness to Experiences & -.052 & .004 & $.499^{* *}$ & $-.267^{* *}$ & $.348^{* *}$ & .048 & - & & & \\
\hline 8.Phubbing ${ }^{\mathrm{CD}}$ & $.574^{* *}$ & $.446^{* *}$ & $-.129^{* *}$ & $-.078^{*}$ & $-.278^{* *}$ & $-.089^{* *}$ & $-.183^{* *}$ & - & & \\
\hline 9.Phubbing ${ }^{\mathrm{PO}}$ & $.519^{* *}$ & $.413^{* *}$ & -.023 & $-.148^{* *}$ & $-.074^{*}$ & $-.128^{* *}$ & -.007 & $.542^{* *}$ & - & \\
\hline 10.Phubbing OVERALL & $.619^{* *}$ & $.487^{* *}$ & $-.081^{*}$ & $-.132^{* *}$ & $-.189^{* *}$ & $-.126^{* *}$ & $-.099^{* *}$ & $.853^{* *}$ & $.901^{* *}$ & - \\
\hline
\end{tabular}

\section{Hierarchical Regression Analysis}

Given the Pearson correlation analysis and Fisher's $r$ to $z$ transformation results illustrated in Table 4, this study sought to determine if BSMAS is the most significant risk factor for communication disturbance (Model 1), phone obsession (Model 2), and overall phubbing behavior (Model 3 ) when compared FoMO and TIPI. To this end, three fourstep hierarchical multiple regression analyses were carried out to analyze the contribution of BSMAS, FoMO, TIPI on Phubbing ${ }^{\mathrm{CD}}$, Phubbing ${ }^{\mathrm{PO}}$, and Phubbing ${ }^{\text {OVERALL }}$ and to examine the study hypotheses. The results of the three regression analyses are summarized in Table 5. All Variance Inflation Factor values ranged from 1.010 to 1.521 , suggesting that no multicollinearity were present in the models. In the first step, gender, class year, major, and questionnaire administration mode were put into the regression model as control variables. The initial models, consisting of only the control variables, accounted for $2.9 \%$ of limited variance in Model $1(F(4,933)=7.041, p<0.01) ; 1.4 \%$ of minimal variance in Model $2(F(4,933)=3.339, p<0.01)$; and $2.3 \%$ of very limited total variance in Model $3(F(4,933)=5.422$, $p<0.01)$. Consistent with the results from the Pearson correlation analysis and the Fisher's $r$ to $z$ transformation, it is worth noting that the addition of the Step 2 variable of BSMAS significantly increased the greatest proportion of variance to $34.7 \%$ in Model $1(F(5,932)=99.167, p<0.01)$, $27.9 \%$ in Model $2(F(5,932)=72.052, p<0.01)$ and $39.6 \%$ in Model $3(F(5,932)=121.991, p<0.01)$. In other words, the $\Delta \mathrm{R}^{2}$ is equal to $31.8 \%(\Delta F(1,932)=454, p<0.01)$, $26.5 \%(\Delta F(1,932)=342.021, p<0.01)$ and $37.3 \%(\Delta F(1$, $932)=574.926, p<0.01)$ for the three respective models. In Step 3, the inclusion of FoMO explained $38.7 \%$ of the total variance in Model $1(F(6,931)=97.852, p<0.01)$, $31.6 \%$ in Model $2(F(6,931)=71.605, p<0.01)$ and $44.5 \%$ in Model $3(F(6,931)=124.339, p<0.01)$. Lastly, TIPI personality traits were added to the regression equations. The Step 4 variables explained $43.8 \%, 32.5 \%$ and $46.6 \%$ of the total variance in Model $1(F(11,926)=65.691, p<0.01)$, Model $2(F(11,926)=40.522, p<0.01)$ and Model $3(F$ $(11,926)=73.426, p<0.01)$, respectively.

The results identified gender as a significant predictor of Model 1 ( $\beta=-0.101, t=-3.490, p<0.01,95 \%$ CI $[-0.902$, $-0.263])$ and Model $3(\beta=-0.088, t=-3.197, p<0.01,95 \%$ CI $[-1.583,-0.376])$, whereas major, class year, and questionnaire administration mode were not significant predictors of any of the Models. Furthermore, BSMAS appeared to be the strongest predictor in Model $1(\beta=0.446, t=15.545$, $p<0.01,95 \%$ CI $[0.256,0.330])$, Model $2(\beta=0.427$, $t=13.587, p<0.01,95 \%$ CI $[0.289,0.387])$, and Model $3(\beta=0.496, t=17.716, p<0.01,95 \%$ CI $[0.561,0.701])$ rather than FoMO and any of the TIPI traits. FoMO also found significant in Model $1(\beta=0.217, t=7.631, p<0.01$, 95\% CI [0.066, 0.112]), Model $2(\beta=0.205, t=6.592$, $p<0.01,95 \%$ CI $[0.071,0.132])$, and Model $3(\beta=0.240$, $t=8.642, p<0.01,95 \% \mathrm{CI}[0.148,0.234])$. Of the five TIPI traits, only extraversion was statistically significant in all Models $(\beta=-0.126, t=-4.161, p<0.01,95 \%$ CI $[-0.213$, $-0.076]),(\beta=-0.089, t=-2.673, p<0.01,95 \%$ CI $[-0.212$, $-0.033])$, and $(\beta=-0.120, t$.

Phubbing ${ }^{\text {OVERALL }}=$ the Phubbing Scale composite score; Phubbing ${ }^{\mathrm{CD}}$ and Phubbing ${ }^{\mathrm{PO}}$ were two subscales of the Phubbing Scale.

BSMAS $=$ Bergen Social Media Addiction Scale; FoMO = Fear of Missing Out Scale; TIPI = Ten-Item Personality Inventory; Phubbing ${ }^{\text {OVERALL }}=$ the Phubbing Scale composite score; Extraversion, Agreeableness, Conscientiousness, Emotional Stability, and Openness to Experience were TIPI personality traits; Phubbing ${ }^{\mathrm{CD}}$ and Phubbing ${ }^{\mathrm{PO}}$ were two subscales of the Phubbing Scale. ${ }^{*} p<0.05$; *** $p<0.01$.

BSMAS = Bergen Social Media Addiction Scale; FoMO = Fear of Missing Out Scale; Extraversion, Agreeableness, Conscientiousness, Emotional Stability, and Openness to Experience were TIPI personality traits; Phubbing ${ }^{\text {OVERALL }}=$ the Phubbing Scale composite score; 
Table 5 Results of multivariate hierarchical regression analysis on the Phubbing

\begin{tabular}{|c|c|c|c|c|c|c|c|c|c|c|c|c|}
\hline \multirow[t]{2}{*}{ Variable } & \multicolumn{4}{|c|}{$\begin{array}{l}\text { Model } 1 \\
\text { Phubbing }\end{array}$} & \multicolumn{4}{|c|}{$\begin{array}{l}\text { Model } 2 \\
\text { Phubbing }\end{array}$} & \multicolumn{4}{|c|}{$\begin{array}{l}\text { Model } 3 \\
\text { Phubbing OVERALL }\end{array}$} \\
\hline & $\beta$ & SE & $\mathrm{R}^{2}$ & $\Delta \mathrm{R}^{2}$ & $\beta$ & SE & $\mathrm{R}^{2}$ & $\Delta \mathrm{R}^{2}$ & $\beta$ & SE & $\mathrm{R}^{2}$ & $\Delta \mathrm{R}^{2}$ \\
\hline \multicolumn{5}{|c|}{ Step 1: $F(4,933)=7.041, p=.000$} & \multicolumn{4}{|c|}{ Step 1: $F(4,933)=3.339, p=.010$} & \multicolumn{4}{|c|}{ Step 1: $F(4,933)=5.422, p=.000$} \\
\hline & & & $.029^{* *}$ & $.029^{* *}$ & & & $.014^{* *}$ & $.014^{* *}$ & & & $.023^{* *}$ & $.023^{* *}$ \\
\hline (Intercept) & & .666 & & & & .807 & & & & 1.294 & & \\
\hline Gender & $-1.072^{* *}$ & .211 & & & $-.831^{* *}$ & .256 & & & $-.171^{* *}$ & .410 & & \\
\hline Class year & -.042 & .086 & & & .162 & .105 & & & .024 & .168 & & \\
\hline Major & -.189 & .124 & & & $-.335^{*}$ & .150 & & & $-.086^{*}$ & .241 & & \\
\hline Administration mode & -.081 & .249 & & & .134 & .301 & & & .004 & .483 & & \\
\hline \multicolumn{5}{|c|}{ Step 2: $F(5,932)=99.167, p=.000$} & \multicolumn{4}{|c|}{ Step 2: $F(5,932)=72.052, p=.000$} & \multicolumn{4}{|c|}{$\begin{array}{l}\text { Step 2: } F(5,932)=121.991, \\
\quad p=.000\end{array}$} \\
\hline & & & $.347^{* *}$ & $.318^{* *}$ & & & $.279^{* *}$ & $.265^{* *}$ & & & $.396^{* *}$ & $.373^{* *}$ \\
\hline (Intercept) & & .631 & & & & .798 & & & & 1.177 & & \\
\hline Gender & $-.135^{* *}$ & .174 & & & $-.073^{*}$ & .219 & & & $-.115^{* *}$ & .324 & & \\
\hline Class year & -.041 & .071 & & & .029 & .090 & & & -.003 & .132 & & \\
\hline Major & -.057 & .102 & & & $-.086^{*}$ & .129 & & & $-.083^{* *}$ & .190 & & \\
\hline Administration mode & .004 & .204 & & & .030 & .258 & & & .021 & .380 & & \\
\hline BSMAS & $.567^{* *}$ & .017 & & & $.517^{* *}$ & .022 & & & $.614^{* *}$ & .033 & & \\
\hline \multicolumn{5}{|c|}{ Step 3: $F(6,931)=97.852, p=.000$} & \multicolumn{4}{|c|}{ Step 3: $F(6,931)=71.605, p=.000$} & \multicolumn{4}{|c|}{$\begin{array}{l}\text { Step 3: } F(6,931)=124.339 \\
\quad p=.000\end{array}$} \\
\hline & & & $.387^{* *}$ & $.040^{* *}$ & & & $.316^{* *}$ & $.037^{* *}$ & & & $.445^{* *}$ & $.049^{* *}$ \\
\hline (Intercept) & & .655 & & & & .832 & & & & 1.207 & & \\
\hline Gender & $-.124^{* *}$ & .169 & & & $-.063^{*}$ & .214 & & & $-.103^{* *}$ & .311 & & \\
\hline Class year & -.027 & .069 & & & .043 & .088 & & & .013 & .127 & & \\
\hline Major & -.030 & .099 & & & -.059 & .126 & & & -.052 & .183 & & \\
\hline Administration mode & .009 & .198 & & & .035 & .252 & & & .026 & .365 & & \\
\hline BSMAS & $.463^{* *}$ & .019 & & & $.417^{* *}$ & .024 & & & $.498^{* *}$ & .035 & & \\
\hline FoMO & $.225^{* *}$ & .012 & & & $.218^{* *}$ & .015 & & & $.252^{* *}$ & .022 & & \\
\hline \multirow{2}{*}{\multicolumn{3}{|c|}{ Step 4: $F(11,926)=65.691, p=.000$}} & & & \multicolumn{4}{|c|}{ Step 4: $F(11,926)=40.522, p=.000$} & \multicolumn{4}{|c|}{$\begin{array}{l}\text { Step 4: } F(11,926)=73.426 \\
\quad p=.000\end{array}$} \\
\hline & & & $.438^{* *}$ & $.051^{* *}$ & & & $.325^{*}$ & $.009^{*}$ & & & $.466^{* *}$ & $.021^{* *}$ \\
\hline (Intercept) & & .965 & & & & 1.272 & & & & 1.822 & & \\
\hline Gender & $-.101^{* *}$ & .163 & & & -.057 & .215 & & & $-.088^{* *}$ & .308 & & \\
\hline Class year & -.031 & .066 & & & .039 & .087 & & & .008 & .125 & & \\
\hline Major & -.027 & .096 & & & -.049 & .126 & & & -.044 & .181 & & \\
\hline Administration mode & .004 & .190 & & & .030 & .251 & & & .021 & .359 & & \\
\hline BSMAS & $.446^{* *}$ & .019 & & & $.427^{* *}$ & .025 & & & $.496^{* *}$ & .036 & & \\
\hline FoMO & $.217^{* *}$ & .012 & & & $.205^{* *}$ & .015 & & & $.240^{* *}$ & .022 & & \\
\hline Extraversion & $-.126^{* *}$ & .035 & & & $-.089^{* *}$ & .046 & & & $-.120^{* *}$ & .066 & & \\
\hline Agreeableness & -.029 & .045 & & & -.025 & .059 & & & -.030 & .085 & & \\
\hline Conscientiousness & $-.139^{* * *}$ & .045 & & & .006 & .059 & & & $-.068^{*}$ & .084 & & \\
\hline Emotional Stability & -.021 & .047 & & & -.040 & .062 & & & -.036 & .089 & & \\
\hline Openness to Experiences & -.054 & .047 & & & .051 & .062 & & & .004 & .088 & & \\
\hline
\end{tabular}

Phubbing ${ }^{\mathrm{CD}}$ and Phubbing ${ }^{\mathrm{PO}}$ were two subscales of the Phubbing Scale; Model $1=$ Phubbing ${ }^{\mathrm{CD}}$ as the dependent variable; Model $2=$ Phubbing ${ }^{\mathrm{PO}}$ as the dependent variable; Model $3=$ Phubbing ${ }^{\text {OVERALL }}$ as the dependent variable. ${ }^{*} p<0.05 ;{ }^{* *} p<0.01$.
$=-4.070, p<0.01,95 \%$ CI $[-0.396,-0.138])$ for Models 1, 2 and 3 respectively, whereas conscientiousness was statistically significant in Model $1(\beta=-0.139$, $t=-4.976, p<0.01,95 \%$ CI $[-0.310,-0.135])$ and Model 3 $(\beta=-0.068, t=-2.497, p<0.05,95 \%$ CI $[-0.376,-0.045])$. 
Interestingly, the TIPI traits, agreeableness, emotional stability, and openness to experience did not contribute significantly in any of the Models.

\section{Discussion}

Societal and psychological issues such as social media addiction and phubbing behaviors have become increasingly prevalent in recent years. It is in this regard that this study seeks to contribute to the rapidly growing literature in this area and to provide critical insight into what factors are contributing to the pathological use of technology in a broader sense. While this is an emerging and rapidly evolving field, research on these prominent issues is still in its infancy. To our knowledge, this was the first study to investigate the relationship among personality traits, the fear of missing out, social media addiction, and phubbing behaviors. Indeed, the present research seeks to illuminate the psychosocial factors behind pathological phubbing behavior and to provide insights into why phubbing behaviors, especially amongst teenagers and young adults, are so prevalent.

To begin, this study provides evidence that gender plays an important role in phubbing behavior; however, in contrast to prior studies which found that females exhibit more severe phubbing behaviors than males do, our study indicates that male students phub more than their female counterparts (Karadağ et al., 2015; Chotpitayasunondh \& Douglas, 2018b; Błachnio \& Przepiorka, 2019). This study forms the following hypotheses in an attempt to explain these genderspecific phubbing behaviors. Firstly, despite our anonymous data collection procedure, a factor that's important to consider is the social desirability bias, a type of response bias that encourages respondents to answer survey questions in a way that will be viewed favorably by others. This causes respondents to overreport "desired" answers and underreport "undesired" answers. For instance, the female students in our sample may have underreported the socially undesirable phubbing activity because they were more affected by the social desirability bias than the male students in our sample (Karadağ et al., 2015; Chotpitayasunondh \& Douglas, 2016).

In addition to the potential biases in our study, genderrelated disparities for addictive behaviors, in general, must also be examined when considering why male students seem to be more prone to exhibiting phubbing behaviors than their female counterparts. Studies from various fields have converged on the finding that males are more susceptible to addictive behaviors than females (Minutillo et al., 2016). For example, specific studies in the area of internet addiction disorders have found that there exists a higher prevalence of internet addiction among males than females (Tsitsika et al., 2014; Mei et al., 2016).
There could also be different societal factors at play; for instance, female adolescents are found to be under more supervision from their families than their male counterparts (Yu \& Shek, 2018). This phenomenon could also imply that internet usage (e.g. social media and smartphone usage) is more tightly regulated for female students in this study than for male students. This hypothesis would also serve to explain gender-related disparities for communication disturbance, phone obsession, and phubbing in this study.

The bivariate correlations revealed significant relationships between multiple research variables and phubbing. In line with previous studies, this study determined a prominent relationship between social media addiction and habitual phubbing behavior (Karadağ et al., 2015; Franchina et al., 2018; Błachnio \& Przepiórka, 2019; Nazir \& Bulut, 2019; Balta et al., 2020). To explain why this is, Salehan and Negahban in 2013 put forth the optimal flow theory, which suggests that social media use is so entertaining for college students to the point where they continue their extensive and pathological use of social media and smartphones even at the expense of apparent consequences, such as phubbing behavior.

To further shed light on why this relationship exists, the study presents the following hypotheses supported by past literature. Firstly, much like the uses and gratification theories that were described in detail previously, the desire for individuals to gratify and satiate their social needs, such as the desire for increased popularity within one's social circle, turns one towards the pathological use of social media and social networking sites (Lee \& Chiou, 2013). Additionally, a study conducted by Oberst et al. in 2016 demonstrated one of the many uses of social media; specifically, the ability of social media platforms to create a social identity for its user. Put simply, people are found to be increasingly dependent on social media platforms and online networking sites to construct their social identities; as opposed to focusing on their identity in person, they instead turn to building and improving their identities online. This phenomenon and the shift in the way people construct their social identities would undoubtedly be associated with an increased prevalence of social media overuse. For the perceived benefits associated with social media stated above- social support, fulfillment of social and psychological needs, construction of social identity - it would certainly be plausible to suggest that for users, keeping up and maintaining social media presence are associated with all of these benefits. An update or a notification, then, would prompt users to habitually and incessantly check their phones, which would inevitably manifest in phubbing behaviors in social situations.

This study determined that FoMO was positively associated with phubbing, which is in line with previous research investigating the relationship between FoMO and phubbing behavior (Chotpitayasunondh \& Douglas, 2016; Blanca 
\& Bendayan, 2018; Davey et al., 2018; Franchina et al., 2018; Balta et al., 2020). The following theories may serve to explain why a positive relationship between FoMO and phubbing exists: 1) uses and gratification theory and 2) relatedness self-determination theory. Firstly, those who have FoMO may turn to social media and smartphones in general to gratify their social needs (Blumler \& Katz, 1974; Ajzen, 1991). The more severe the FoMO is, the more susceptible people are to depend on smartphones, and in turn, the more likely they are to exhibit phubbing behaviors (Balta et al., 2020). It would be reasonable to suggest that according to the uses and gratification theory (Ryan et al., 2014), people with FoMO would be more likely to depend on smartphones and exhibit phubbing behaviors because previous studies have found that college students turn to social media to fulfill their specific emotional and psychological needs (Wang $\&$ Wang, 2013). Secondly, assuming that those with FoMO desire the feelings of connectedness/relatedness with their friends, it would be reasonable to suggest that in order to overcome this FoMO and to satisfy their desire to belong somewhere, people are motivated to go onto social media platforms and as a consequence, end up phubbing others in a social setting (ten Cate, 2013).

This study exhibited a negative connection between the TIPI personality traits and habitual phubbing behavior. More specifically, this study found that among the five traits of TIPI, conscientiousness was most inversely correlated with Phubbing ${ }^{\mathrm{CD}}$ and Phubbing ${ }^{\mathrm{TOTAL}}$, which is consistent with evidence from the US (Chotpitayasunondh \& Douglas, 2018b). By way of explanation, individuals with poor consciousness or awareness of internal and external existence are by consequence, more likely to have poor discipline, organization, etc. which manifests in communication disturbance and phubbing behaviors in societal settings. Moreover, previous studies which sought to shed light on the implications of the various TIPI traits have revealed that the lack of conscientiousness in an individual may cause problems in regard to communication (Jensen-Campbell \& Malcolm, 2007; Juhász, 2010). Conversely, Lee et al. (2019) determined that conscientious individuals are responsible in regard to interpersonal relationships and seek to establish more constructive relationships with others. Given the above-mentioned study findings, it would be expected that conscientiousness would have an inverse relationship with communication disturbance and phubbing behaviors.

On the other hand, this study showed that agreeableness was most inversely correlated with Phubbing ${ }^{\mathrm{PO}}$. This is also in accordance with the assertion in Schermer and Martin's (2019) research that agreeableness is negatively correlated with smartphone use. To explain this apparent relationship between agreeableness (or lack thereof) and phone obsession, this study posits that less agreeable individuals are more isolated in their real-life relations (Panda,
2016) and may seek to compensate for this feeling of loneliness and isolation by turning to smartphone usage. This compensatory smartphone usage would naturally increase the likelihood of phone obsession and phubbing behaviors.

The empirical results of the hierarchical multiple regression analyses of this study further substantiated that the BSMAS holds the most predictive power for Phubbing ${ }^{\mathrm{CD}}$, Phubbing ${ }^{\mathrm{PO}}$, and Phubbing ${ }^{\text {OVERALL }}$, which confirms this study's hypothesis. This should come as no surprise as correlation analysis demonstrated that BSMAS was distinct from the other study variables and that BSMAS was most strongly associated with phubbing behaviors. To put it concisely, this study's analyses point to the role of social media addiction in phubbing behaviors in a social context.

FoMO was shown to be associated with phubbing in the current study, supporting this study's hypothesis. Although significant, FoMO did not possess as much predictive power as BSMAS did on phubbing. The predictive power of FoMO on phubbing, albeit weak, is unsurprising as individuals turn to smartphone/internet use as a coping mechanism to deal with their fears of missing out, and this mechanism may eventually increase the prevalence of phubbing behaviors.

In alignment with this study's hypothesis, TIPI was also shown to be significant in the present study. However, it is worth noting that the addition of the five traits of TIPI did not result in a pronounced increase in the proportion of variance. As communication disturbance, phone obsession, and phubbing behavior concerns online identities, the authors suspect that the TIPI traits or offline identities, might not be accurate representations of online identities (Ellison et al., 2006). If this is indeed true, the discrepancy between offline and online identities may complicate study findings. Future research should consider the role of congruency or incongruency of offline and online identities when determining whether individuals with certain personality traits are more susceptible to phubbing behaviors. Notably, extraversion was most associated with phubbing behavior among the five traits studied. Specifically, students who are less extroverted exhibited higher levels of phubbing behaviors relative to their more extroverted counterparts. In an effort to explain why this inverse relationship exists, the authors posit the following hypotheses. Firstly, introverted individuals, by nature, have a more difficult time befriending others than extroverted individuals. The lack of in-person or offline friends may prompt these individuals to turn to online platforms and mediums to form friendships, which would ultimately contribute to an observed increase in phubbing behavior. Introverted individuals may also be more socially anxious (Ehrenberg et al., 2008) or lack self-confidence (Luyckx et al., 2013) in conventional in-person social settings, which would likewise encourage them to turn to the online alternatives. 
Interestingly, as evidenced by regression analysis, the sociodemographic variables least influenced phubbing behaviors.

\section{Limitations and Future Research}

Several limitations need to be addressed when interpreting study findings. Firstly, sample collection and the study sample itself must be considered. Specifically, Taiwanese university students were utilized as the study sample, which hinders the generalizability of the conclusions drawn from this study. Another limitation to the generalizability of the findings is that a convenience sample was utilized, which indicates that our study sample was not representative of all Taiwanese university students. The self-reported nature of the questionnaires used also places limitations on the validity and reliability of the study findings. Hence, future research should investigate the risk factors of phubbing behaviors using a more representative sample and utilize external measures and multiple assessment tools to improve upon the generalizability and the validity of the conclusions drawn. Subsequent studies may also be conducted using different study samples from different regions to determine whether cultural or regional differences play a role in phubbing behavior. Moreover, the results of this cross-sectional study are unable to inform the cause and effect or the directional nature of the relationships in our study variables. Consequently, future studies should utilize longitudinal research designs to confirm causal relationships between the variables in the current study.

As previously mentioned, future research should also explore the impact, or the lack thereof, of offline/online identity incongruence in determining which individuals are more susceptible to phubbing behaviors.

Finally, future studies are encouraged to investigate more determinants and consequences across different study samples in various social settings. The variables in the present study could only explain $43.8 \%$ of phubbing behavior which suggests that the unexplained variance may be attributed to other unidentified variables.

Despite the limitations, this study makes a significant contribution to the existing literature on issues concerning social media addiction, phubbing behaviors, etc. that have become increasingly prominent in modern society. The present study also sheds light on previously unknown relationships among personality traits, the fear of missing out, social media addiction, and phubbing behaviors.

\section{Conclusion}

Overall, the present study is the first to conceptualize connections between social media addiction, fear of missing out, personality traits, and phubbing behaviors. In spite of the increasingly prevalent societal and psychological issues brought about by technological advancements in the past century, there exists very little research on the psychosocial factors that precede the problematic usage of technology. Indeed, the conclusions and implications of this work could prove to be critical in determining antecedents to phubbing and in assessing potential risk factors for pathological smartphone use in general.

It is in this regard that the present study seeks to remedy these issues and to provide insight for appropriate interventions to put in place to establish and strengthen interpersonal relationships in an increasingly disconnected world.

Author Contributions LCC and TCT contributed to data collection, data analysis, interpretation, manuscript preparation and editing, ET contributed to the conceptualization and the study design of the study, introduction and conclusion sections of the manuscript.

Data Availability The datasets generated during and/or analyzed during the current study are available from the corresponding author on reasonable request.

\section{Declarations}

Ethical Statement All procedures performed in studies involving human participants were in accordance with the ethical standards of the institutional and/or national research committee and with the 1964 Helsinki declaration and its later amendments or comparable ethical standards. All procedures performed were in accordance with the ethical standards of the National Formosa University Ethics Guides. This article does not contain any studies with animals performed by any of the authors.

Informed Consent Informed consent was obtained from all individual participants included in the study.

Conflict of Interest The authors declare no conflict of interest.

Open Access This article is licensed under a Creative Commons Attribution 4.0 International License, which permits use, sharing, adaptation, distribution and reproduction in any medium or format, as long as you give appropriate credit to the original author(s) and the source, provide a link to the Creative Commons licence, and indicate if changes were made. The images or other third party material in this article are included in the article's Creative Commons licence, unless indicated otherwise in a credit line to the material. If material is not included in the article's Creative Commons licence and your intended use is not permitted by statutory regulation or exceeds the permitted use, you will need to obtain permission directly from the copyright holder. To view a copy of this licence, visit http://creativecommons.org/licenses/by/4.0/.

\section{References}

Ajzen, I. (1991). The theory of planned behavior. Organizational Behavior and Human Decision Processes, 50(2), 179-211. 
Andreassen, C. S., Griffiths, M. D., Gjertsen, S. R., Krossbakken, E., Kvam, S., \& Pallesen, S. (2013). The relationships between behavioral addictions and the five-factor model of personality. Journal of Behavioral Addictions, 2(2), 90-99.

Andreassen, C. S., Billieux, J., Griths, M. D., Kuss, D. J., Demetrovics, Z., Mazzoni, E., \& Pallesen, S. (2016). The relationship between addictive use of social media and video games and symptoms of psychiatric disorders: A large-scale cross-sectional study. Psychology of Addictive Behaviors, 30(2), 252-262.

Balcerowska, J. M., Bereznowski, P., Biernatowska, A., Atroszko, P. A., Pallesen, S., \& Andreassen, C. S. (2020). Is it meaningful to distinguish between Facebook addiction and social networking sites addiction? Psychometric analysis of Facebook addiction and social networking sites addiction scales. Current Psychology, 28(1), 1-14.

Balta, S., Emirtekin, E., Kircaburun, K., \& Griffiths, M. D. (2020). Neuroticism, trait fear of missing out, and phubbing: The mediating role of state fear of missing out and problematic Instagram use. International Journal of Mental Health and Addiction, 18(3), 628-639.

Bányai, F., Zsila, Á., Király, O., Maraz, A., Elekes, Z., Griffiths, M. D., Andreassen, C. S., \& Demetrovics, Z. (2017). Problematic social media use: Results from a large-scale nationally representative adolescent sample. PLoS One, 12(1), 10-14.

Beaton, D. E., Bombardier, C., Guillemin, F., \& Ferraz, M. B. (2000). Guidelines for the process of cross-cultural adaptation of selfreport measures. Spine, 25(24), 3186-3191.

Bianchi, A., \& Phillips, J. G. (2005). Psychological predictors of problem mobile phone use. Cyberpsychology \& Behavior, 8(1), 39-51.

Blanca, M. J., \& Bendayan, R. (2018). Spanish version of the phubbing scale: Internet addiction, Facebook intrusion, and fear of missing out as correlates. Psicothema, 30(4), 449-454.

Błachnio, A., \& Przepiorka, A. (2019). Be aware! If you start using facebook problematically you will feel lonely: Phubbing, and facebook intrusion. A cross-sectional study. Social Science Computer Review, 37(2), 270-278.

Blumler, J. G., \& Katz, E. (1974). The uses of mass communications: Current perspectives on gratifications research. Sage Publications.

Butt, S., \& Phillips, J. G. (2008). Personality and self-reported mobile phone use. Computers in Human Behavior, 24(2), 346-360.

Chen, I.-H., Strong, C., Lin, Y.-C., Tsai, M.-C., Leung, H., Lin, C.-Y., Amir, H., Pakpour, A. H., \& Griffiths, M. D. (2020). Time invariance of three ultra-brief internet-related instruments: Smartphone application-based addiction scale (SABAS), Bergen social media addiction scale (BSMAS), and the nine-item internet gaming disorder scale- short form (IGDS-SF9)(study part B). Addictive Behaviors, 101(105960), 1-8.

Chotpitayasunondh, V., \& Douglas, K. M. (2016). How "phubbing" becomes the norm: The antecedents and consequences of snubbing via smartphone. Computers in Human Behavior, 63, 9-18.

Chotpitayasunondh, V., \& Douglas, K. M. (2018a). The effects of "phubbing" on social interaction. Journal of Applied Social Psychology, 48(6), 304-316.

Chotpitayasunondh, V., \& Douglas, K. M. (2018b). Measuring phone snubbing behavior: Development and validation of the generic scale of phubbing (GSP) and the generic scale of being phubbed (GSBP). Computers in Human Behavior, 88(1), 5-17.

Davey, A., Raghav, S. K., Singh, J. V., Singh, N., Blanchio, A., \& Przepiórkaa, A. (2018). Predictors and consequences of "phubbing" among adolescents and youth in India: An impact evaluation study. Journal of Family and Community Medicine, 25(1), 35-42.

Ehrenberg, A., Juckes, S., White, K. M., \& Walsh, S. P. (2008). Personality and self-esteem as predictors of young people's technology use. Cyberpsychology \& Behavior, 11(6), 739-741.
Eisinga, R., te Grotenhuis, M., \& Pelzer, B. (2013). The reliability of a two-item scale: Pearson, Cronbach, or spearman-Brown? International Journal of Public Health, 58(4), 637-642.

Ellison, N. B., Heino, R. D., \& Gibbs, J. L. (2006). Managing impressionsonline: Self-presentation processes in the online dating environment. Journal of Computer-Mediated Communication, 11(2), $415-441$

Fornell, C., \& Larcker, D. F. (1981). Evaluating structural equation models with unobservable variables and measurement error. Journal of Marketing Research, 18(1), 39-50.

Franchina, V., Vanden Abeele, M., van Rooij, A. J., Lo Coco, G., \& De Marez, L. (2018). Fear of missing out as a predictor of problematic social media use and phubbing behavior among Flemish adolescents. International Journal Environment Research and Public Health, 15(10), 2319.

Garson, G. D. (2012). Testing statistical assumptions. Statistical Associates Publishing.

Gokler, M. E., Aydin, R., Unal, E., \& Metintas, S. (2016). Determining validity and reliability of Turkish version of fear of missing out scale. Anatolian Journal of Psychiatry, 17(1), 53-59.

Gosling, S. D., Rentfrow, P. J., \& Swann, W. B. (2003). A very brief measure of the big-five personality domains. Journal of Research in Personality, 37(6), 504-528.

Griffiths, M. (2000). Internet addiction-time to be taken seriously? Addiction Research, 8(5), 413-418.

Hong, F.-Y., Chiu, S.-I., \& Huang, D.-H. (2012). A model of the relationship between psychological characteristics, mobile phone addiction and use of mobile phones by Taiwanese university female students. Computers in Human Behavior, 28(6), 2152-2159.

Jensen-Campbell, L. A., \& Malcolm, K. T. (2007). The importance of conscientiousness in adolescent interpersonal relationships. Personality and Social Psychology Bulletin, 33(3), 368-383.

Juhász, M. (2010). Influence of personality on teamwork behaviour and communication. Social and Management Sciences, 18, 63-77.

Karadağ, E., Tosuntaş, Ş. B., Erzen, E., Duru, P., Bostan, N., Şahin, B. M., Çulha, I., \& Babadağ, B. (2015). Determinants of phubbing, which is the sum of many virtual addictions: A structural equation model. Journal of Behavioral Addictions, 4(2), 60-74.

Karadağ, E., Tosuntaş, S. B., Erzen, E., Duru, P., Bostan, N., Şahin, B. M., Çulha, I., \& Babadağ, B. (2016). The virtual world's current addiction: Phubbing. The Turkish Journal on Addictions, 3(2), 250-269.

Kayiş, A. R., Satici, S. A., Yilmaz, M. F., Şimşek, D., Ceyhan, E., \& Bakioğlu, F. (2016). Big five-personality trait and internet addiction: A meta-analytic review. Computers in Human Behaviour, $63,35-40$.

Kircaburun, K., Alhabash, S., Tosuntaş, Ş. B., \& Griffiths, M. D. (2020). Uses and gratifications of problematic social media use among university students: A simultaneous examination of the big five of personality traits, social media platforms, and social media use motives. International Journal of Mental Health and Addiction, 18(3), 525-547.

Kline, R. B. (2011). Principles and practice of structural equation modeling (3rd ed.). Guilford Press.

Kuss, D. J., Griffiths, M. D., \& Binder, J. F. (2013). Internet addiction in students: Prevalence and risk factors. Computers in Human Behavior, 29(3), 959-966.

Lee, C. C., \& Chiou, W. B. (2013). Experimental evidence showing the relation of affiliation needs to the idea of online social networking. Cyberpsychology, Behavior and Social Networking, 16(6), 419-422.

Lee, M., Murphy, K., \& Andrews, G. (2019). Using media while interacting face-to-face is associated with psychosocial well-being and personality traits. Psychological Reports, 122(3), 944-967. 
Leung, H., Pakpour, A. H., Strong, C., Lin, Y. C., Tsai, M. C., Griffiths, M. D., Lin, C. Y., \& Chen, I. H. (2020). Measurement invariance across young adults from Hong Kong and Taiwan among three internet-related addiction scales: Bergen social media addiction scale (BSMAS), smartphone application-based addiction scale (SABAS), and internet gaming disorder scale-short form (IGDSSF9) (study part a). Addictive Behaviors, 101(105969), 1-9.

Luyckx, K., Klimstra, T. A., Duriez, B., Van Petegem, S., \& Beyers, W. (2013). Personal identity processes from adolescence through the late 20s: Age trends, functionality, and depressive symptoms. Social Development, 22(4), 701-721.

Mei, S., Yau, Y. H., Chai, J., Guo, J., \& Potenza, M. N. (2016). Problematic internet use, well-being, selfesteem and self-control: Data from a high-school survey in China. Addictive Behaviors, $61,74-79$.

Minutillo, A., Pacifici, R., Scaravelli, G., De Luca, R., Palmi, I., Mortali, C., Mastrobattista, L., \& Berretta, P. (2016). Gender disparity in addiction: An Italian epidemiological sketch. Annali dell'Istituto superiore di sanità, 52(2), 176-183.

Nazir, T., \& Bulut, S. (2019). Phubbing and what could be its determinants: A dugout of literature. Psychology, 10(2), 819-829.

Oberst, U., Renau, V., Chamarro, A., \& Carbonell, X. (2016). Gender stereotypes in Facebook profiles: Are women more female online? Computers in Human Behavior, 60, 559-564.

Panda, S. (2016). Personality traits and the feeling of loneliness of post-graduate university students. The International Journal of Indian Psychology, 3(3), 27-37.

Przepiorka, A., Siu, N. Y. F., Szcześniak, M., Timoszyk-Tomczak, C., Le, J. J., \& Muñoz, M. P. (2020). The relation between personality, time perspective and positive orientation in Chile, Hong Kong, and Poland. Journal of Happiness Studies, 21(3), 1081-1101.

Przybylski, A. K., Murayama, K., DeHaan, C. R., \& Gladwell, V. (2013). Motivational, emotional, and behavioral correlates of fear of missing out. Computers in Human Behavior, 29(4), 1841-1848.

Ryan, T., Chester, A., Reece, J., \& Xenos, S. (2014). The uses and abuses of Facebook: A review of Facebook addiction. Journal of behavioral addictions. Advance online publication, 3(3), 133-148.

Salehan, M., \& Negahban, A. (2013). Social networking on smartphones: When mobile phones become addictive. Computers in Human Behavior, 29(3), 2632-2639.
Schermer, J. A., \& Martin, N. G. (2019). A behavior genetic analysis of personality and loneliness. Journal of Research in Personality, 78(6), 133-137.

Stead, H., \& Bibby, P. A. (2017). Personality, fear of missing out and problematic internet use and their relationship to subjective wellbeing. Computers in Human Behavior, 76, 534-540.

ten Cate, O. T. J. (2013). Why receiving feedback collides with self determination. Advances in Health Sciences Education, 18(4), 845-849.

Tsitsika, A., Janikian, M., Schoenmakers, T. M., Tzavela, E. C., Olafsson, K., Wojcik, S., Macarie, G. F., Tzavara, C., \& Richardson, C. (2014). Internet addictive behavior in adolescence: A crosssectional study in seven European countries. Cyberpsychology, Behavior and Social Networking, 17(8), 528-535.

Wang, E. S.-T., \& Wang, M. C.-H. (2013). Social support and social interaction ties on internet addiction: Integrating online and offline contexts. Cyberpsychology, Behavior and Social Networking, 16(11), 843-849.

Xie, X., Wang, Y., Wang, P., Zhao, F., \& Lei, L. (2018). Basic psychological needs satisfaction and fear of missing out: Friend support moderated the mediating effect of individual relative deprivation. Psychiatry Research, 268(10), 223-228.

Young, K. S. (1999). The research and controversy surrounding internet addiction. Cyberpsychology \& Behavior, 2(5), 381-383.

Yu, L., \& Shek, D. T. L. (2018). Testing longitudinal relationships between internet addiction and well-being in Hong Kong adolescents: Cross-lagged analyses based on three waves of data. Child Indicators Research, 11(1), 1545-1562.

Zamani, B. E., Abedini, Y., \& Kheradmand, A. (2011). Internet addiction based on personality characteristics of high school students in Kerman, Iran. Addiction and Health, 3(3-4), 85-91.

Zhou, Y. Y., Li, D. P., Li, X., Wang, Y. H., \& Zhao, L. Y. (2016). Big five personality and adolescent internet addiction: The mediating role of coping style. Addictive Behaviors, 64, 42-48.

Publisher's note Springer Nature remains neutral with regard to jurisdictional claims in published maps and institutional affiliations. 